\section{PRECISION HYGROMETRY WITH A WET-BULB}

\author{
By DR. W. LAWRENCE BALLS, C.B.E., F.R.S. \\ Cotton Research Board, Giza, Cairo
}

\begin{abstract}
A METHOD was required whereby the relative humidity (R.H.) of air in equilibrium with eotton samples could be determined to one half of one per cent. The apparatus had to maintain its zero and its calibration year in and year out, so as to make it suitable for routine employment in a testing laboratory. Certified thermometers which are used within the limits of ordinary room temperature changes can fulfil this condition, so the wet-anddry-bulb method was investigated and improved until it became precise. So far as cotton-testing is concerned, the work is at present in suspense, but the wet-bulb hygrometer was tried out during a couple of years and seems to merit description.
\end{abstract}

The following are the essential components. An aspirator, which is a diaphragm-type variable speed air-pump, is required if re-circulation of the air is needed. The temperature of the air at the sampling point is noted by a thermometer mounted with its bulb concentric to the intake of the aspirator. This air then passes through a long coil of copper tube immersed in a water-bath, where it comes to the temperature of the water and so almost stabilizes the next reading to be taken, that of the dry-bulb proper ; incidentally, this minimizes reading errors on the dry-bulb. This partial stability is only due to the large volume of the water-bath (about ten litres), its temperature not being regulated at all ; obviously, if its temperature is below the dew-point of the incoming air, warm water must be used. The wetbulb and dry-bulb thermometers are mounted inside two vertical and parallel glass encasing tubes, sealed below and stoppered at the top, with side-tube inlet, side-tube exit, and a side-tube connexion between them. The lower ends and the side-tubes are all immersed in the water-bath, thereby helping to screen the thermometer bulbs from external radiation. Air coming from the copper pipe impinges on the dry-bulb at right angles through the inlet tube, then passes through the interconnecting tube; cemented inside this is a stainless steel liner which standardizes its diameter and hence the rate of flow at which the air impinges on the foot of the wet-bulb in the other encasing tube. The air escapes from the latter through the exit side-tube, which is similarly lined, but with a stainless steel tube of slightly smaller diameter ; thus a small air pressure is built up in the wet-bulb encasing tube; this exit tube is aligned to withdraw the air from the top of the wet-bulb wick, so giving very turbulent air-flow over the wick at a known final velocity; actually six metres per second is used. The volume of air passed through or around the circuit is indicated by a venturi throat inserted therein with an inclined mercury manometer attached; this is calibrated by direct collection of the air discharged and adjusted by inolining the manometer so that a single marked point thereon indicates six litres per minute in our particular lay-out; if the reading is off this marked point, the pump-speed is regulated accordingly.

Certain precautions are taken in the use of these essential components. The encasing tubes and venturi meter are enclosed in a glass-fronted cupboard resting on top of the water-bath tank; the roof of the cupboard is hinged for access to the encasing tubes. Thermometers of the sling-psychrometer type are used, with small cylindrical bulbs, taking less than two minutes to reach equilibrium; the lapse of this time is most conveniently indicated by using a sandglass, to avoid confusion of thermometer figures with elock figures in rapid working. This type of thermometer was more easily obtained in Fahrenheit calibration, and is read to estimated tenths of a degree Fahrenheit in order to get the accuracy required; this is done by simple lenses in antiparallax mountings, which slide on the glass eupboard-front. It having been found that confusion was liable to happen between tens and fives on the scale of degrees when reading through lenses, the thermometer stems were painted red from 65 to 70 , 75 to 80 , and so on. A very convenient standard wick was adopted by removing the braided cotton cover from electric wiring flex of suitable size; this was boiled in caustic soda and washed with distilled water while stretched on glass tubing of the same diameter as the thermometer bulb; after drying, it was cut into lengths slightly longer than a bulb, slipped on the bulb and slightly stretched to make it hold closely.

With the apparatus thus set up, and using appropriate tables or graphs, we first obtain the 'grams of moisture per kilogram of air' from the depression of the wet-bulb, and then refer this to the temperature of the intake thermometer, so finding the relative humidity at the intake. The standard error of the determination is dependent on reading the thermometers to one tenth of one degree, and so is greater with damp cold air than with hot dry air ; this error can be reduced by using a warm water-bath, and in average conditions is less than $\frac{1}{2}$ per cent R.H. The absolute accuracy of the result, as distinct from the relative accuracy with which we were immediately concerned, is necessarily contingent on the accuracy of the tables of hygrometry. In the last resort, these should be worked out anew for the particular instrument design employed, with the correct airspeed.

However, the lay-out described, though completely standardized, can only be effective if the evaporating abilities of the wick itself are also standardized, and the technique whereby the wick-properties are stabilized over periods of a year and more constitutes our principal improvement in wet-bulb hygrometry. It has been noted by meteorologists that wet-bulb wicks deteriorate during use, the depression becoming less than it should be. This had been ascribed to dust and dirt adhering to the wick. A weekly change of wick is routine in some meteorological screens. Using our apparatus under the very stringent conditions of cotton-air-moisture determination checked against actual oven-tests, on many samples every day, we found at first that a weekly change of the wick sufficed. But this was during the winter, in Alexandria, and as the observations continued into the hot weather we found evidence of wick deterioration arriving more rapidly, until by June the results were falsified even by the second day of use. This suggested a biological factor in the deterioration.

The encasing tube of the wet-bulb thermometer was therefore expanded into a biggish bulb at the bottom, this bulb being completely immersed in the waterbath, and itself filled with a $0 \cdot 1$ per cent solution of mercuric chloride, as an antiseptic against bacteria and fungi, which nevertheless was so dilute as not to behave unlike pure water during short runs. The 
stcpper at the tcp of the encasing tube was expanded into a glass saucer, closed by a thin and slack rubber diaphragm from toy balloons. The wet-bulb thermometer was suspended from this diaphragm with appropriate stops to limit its range of up and down movements. Normally it remained with its bulb immersed in the mercuric chloride solution. When the air-pump was started the small pressure built up in the encasing tube caused the diaphragm to distend; this lifted the thermometer with its dripping wet wick into the turbulent air-flow and held it steady in position ready for reading after two minutes had elapsed. The wicks used will hold the depression constant for some five minutes or more, according to conditions, before they show signs of drying up. The evaporation from the solution is negligible except while the air-stream is flowing, and it is then of the order of three milligrams of water per test, so that the solution has eventually to be topped up with distilled water; actually about once a week when in continuous daily use. The relative humidity of the outgoing air is perceptibly increased by this added water, which is immaterial unless re-circulation is employed, when small corrections become necessary, dependent on the volume of air in the system.

The stability of the system over long periods of time, and its low standard error, are its outstanding advantages. Its accuracy would seem to be of the same order as that of the more difficult dew-point determinations. Additionally, it is often very convenient to be able to place the intake in some particular locality, with a long rubber tube to the apparatus, and examine the humidity in different parts of a room, or underground in the soil, and so forth.

\section{ROYAL PHOTOGRAPHIC SOCIETY'S ANNUAL EXHIBITION}

$\mathrm{T}$

HE eighty-eighth Annual Exhibition of the Royal Photographic Society of Great Britain was opened on September 3 by H.R.H. King Peter of Yugoslavia. The Exhibition is being held at the Society's premises at 16 Princes Gate, London, S.W.7, and will ke open to the public between $10 \mathrm{a} . \mathrm{m}$. and 5 p.m. until October 23 inclusive. A new experiment being tried this year is Sunday opening. The Exhibition is being opened on alternate Sundays, September 12 and 26 and October 10 from 2 p.m. until 5 p.m. This is to enable members and others who, on account of their war work or other causes, are unable to travel or find time to see the Exhibition on weekdays.

The Exhibition, as is usual, covers all branches of photography from the purely pictorial to the use of photosensitive material in research. While one cannot but admire some of the pictorial work and note that both the quantity and quality of previous years seem well maintained, one can regret that the same cannot be said of the 'scientific' exhibits. The best represented section is probably "Natural History", in which are shown many fine examples of wild life (both plant and animal) in their natural habitats. The War has evidently had little effect on the patience of the photographer of Nature.

Colour photography also seems to have suffered little, being represented by a number of prints on paper some of which are of excellent quality. Many transparencies are shown, including one case of
"Scientific Colour Transparencies" which are mainly of biological subjects, or photomicrographs by polarized light.

Of special interest this year are two exhibits in the Trade Section. One is on mass miniature radiography by Ilford Limited and the other on the 'Kodak' transfer sensitizing process. The attack on tukerculosis depends for its success on early diagnosis, so that the possibility of mass miniature radiography should be a milestone on the road to the control of the disease. In the absence of means of refracting or specularly reflecting X-rays it has been generally necessary to obtain full-size pictures of the subject. Quite apart from the cost of such large photographs as are necessary when dealing with the human chest, the handling of large numbers of $15 \mathrm{in.} \times 12 \mathrm{in}$. films becomes a serious matter. The possibility of photographing, with an ordinary camera and film sensitive to light, the fluorescent image produced by $\mathrm{X}$-rays falling on a fluorescent screen was shown many years ago, but it has only relatively recently been possible to reduce this process to one of routine requiring only a short exposure of the patient to $\mathrm{X}$-rays. This development has been due largely to the increase in aperture of lenses and the increase in speed of photographic film. The image of the chest is contained in an area of film only one inch square, so that a large number ean be accommodated on $35 \mathrm{~mm}$. cine-film which can be easily handled in any length.

Mass miniature radiography units have been developed and have been adopted by the Ministry of Health for national service purposes. The equipment and method of working is illustrated in detail by pictures and models. It must be emphasized that the method is not intended as one for diagnosis but to enable a large number of presumably normal individuals to ke examined to detect unsuspected abnormalities which ean, where necessary, be the subject of full-scale radiological and clinical examination.

The exhibit by Kodak Limited is of the 'Kodak' transfer sensitizing process by means of which any flat sheet material can be sensitized. The chief application is in the marking of templates. The conventional method consists in hand-scribing the design from a scale drawing, which requires a skilled and experienced operator. By the method illustrated the material on which the template is to be marked is first lacquered and the sensitizing paper is then squeegeed to it by means of a roller squeegee. The temporary paper support is stripped off when the sensitive surface is required for use. The required design may be drawn on translucent paper, or should the original drawing be on an opaque support an intermediate negative is necessary or the 'reflex transfer' process may be used. The exposed layer is then developed on the metal or other support to yield an image of the required design.

The process is illustrated by a series of specimens contributed by Handley Page, Ltd., including an $8 \mathrm{ft}$. $\times 4 \mathrm{ft}$. metal section bearing designs reproduced by this process.

The process also lends itself to the production of such things as name-plates, instrument dials, etc. Direct use may be made of the photographic image, but more robust forms may be made by converting the image into a gelatin stencil which allows the undercoat lacquer to be dissolved away, leaving the design in lacquer, or the bared metal may be plated or etched and filled. Typical examples of this applica- 